\title{
REVIEW
}

\section{BRUCELLA PERITONITIS IN PERITONEAL DIALYSIS: A CASE REPORT AND REVIEW OF THE LITERATURE}

\author{
Yalcin Solak, ${ }^{1}$ Zeynep Biyik, ${ }^{1}$ Sinan Demircioglu, ${ }^{2}$ Ilker Polat, ${ }^{2}$ Nejdet Genc, ${ }^{3}$ Kultigin Turkmen, ${ }^{1}$ \\ and Suleyman Turk ${ }^{1}$ \\ Division of Nephrology, ${ }_{r}^{1}$ Department of Internal Medicine, ${ }^{2}$ and Department of Infectious Diseases, ${ }^{3}$ \\ Meram School of Medicine, Selcuk University, Meram, Turkey
}

\begin{abstract}
Brucellosis is a zoonotic infection that humans contract usually by ingestion of unpasteurized milk and milk products or by direct contact with raw infected animal products. Infection is endemic in many countries, including Turkey. Being a systemic disease, brucellosis may affect almost any part of the body. The peritoneum is a site rarely involved in brucellosis. Most peritonitis episodes involving Brucella species have been spontaneous cases reported in cirrhotic patients with ascites. To our knowledge, the literature contains only 5 cases of Brucella peritonitis related to continuous ambulatory peritoneal dialysis. Here, we report Brucella peritonitis in a continuous ambulatory peritoneal dialysis patient, and we discuss the relevant literature.
\end{abstract}

Perit Dial Int 2012; 32(2):126-130 www.PDIConnect.com doi: 10.3747/pdi.2011.00056

KEY WORDS: Brucellosis; CAPD; peritonitis.

$\mathrm{B}$ rucellosis is a zoonotic infection that humans contract usually by direct contact with raw infected animal products and materials, by ingestion of unpasteurized milk and milk products, or by inhalation of aerosols (1). This systemic infection can involve every organ system, including epididymis, testes, liver, bones, spleen, meninges, endocardium, and so on. Peritonitis from Brucella species has rarely been reported in the

Correspondence to: Y. Solak, Selcuk Universitesi, Meram Tip Fakultesi, Hemodiyaliz Sekreterligi, 42080, Meram, Konya, Turkey.

yalcinsolakmd@gmail.com

Received 9 March 2011; accepted 3 August 2011 literature; most cases involve spontaneous bacterial peritonitis in cirrhotic patients (2-6). In the setting of continuous ambulatory peritoneal dialysis (CAPD), Brucella peritonitis is exceedingly rare. To the best of our knowledge, only 5 cases of Brucella peritonitis in CAPD have been reported to date (7-10). Here, we report a case of Brucella peritonitis without systemic symptoms that was managed without removal of the peritoneal dialysis catheter. We also discuss important aspects of presentation and management in previously reported cases.

\section{CASE REPORT}

A 48-year-old man who had been undergoing CAPD for 3 years presented with complaints of abdominal pain, abdominal bloating, and constipation of 2 weeks' duration. With a preliminary diagnosis of CAPD-related peritonitis, the patient was given two 1-g doses of vancomycin on an outpatient basis. After an increase in the severity of abdominal pain, he was admitted to our nephrology clinic.

On physical examination, no fever or hypotension was evident. The abdomen was mildly tender to palpation. Other aspects of the physical examination were unremarkable, and the peritoneal effluent was not cloudy. The patient's white blood cell (WBC) count was $820 / \mathrm{mm}^{3}\left(0.82 \times 10^{9} / \mathrm{L}\right.$; normal value: $\left.<0.03 \times 10^{9} / \mathrm{L}\right)$, with $1 \%$ neutrophils, $48 \%$ lymphocytes, and $36 \%$ monocytes. Gram stain showed numerous leucocytes, but no micro-organisms. Laboratory findings included a blood urea nitrogen level of $84 \mathrm{mg} / \mathrm{dL}$; creatinine, $5.2 \mathrm{mg} / \mathrm{dL}$; 
WBCs, $7.16 \times 10^{3} / \mathrm{mm}^{3}\left(7.16 \times 10^{9} / \mathrm{L}\right)$; hemoglobin, $13 \mathrm{~g} /$ $\mathrm{dL}$; platelet count, $373 \times 10^{3} / \mathrm{mm}^{3}$; C-reactive protein, $54 \mathrm{mg} / \mathrm{L}$; procalcitonin, $0.17 \mathrm{ng} / \mathrm{mL}$; and erythrocyte sedimentation rate, $69 \mathrm{~mm} / \mathrm{h}$. Liver function tests were normal. Abdominal ultrasonography and upright abdominal radiography revealed no abnormal findings. The exit site of the Tenckhoff catheter was clean. An investigation of the peritoneal effluent for the presence of acidoresistant bacilli was negative.

Pending culture results, antibiotic treatment comprising intravenous ceftriaxone $1 \mathrm{~g}$ twice daily and intravenous vancomycin $1 \mathrm{~g}$ every 96 hours was commenced. $0 \mathrm{n}$ the 12th day, the WBC count in peritoneal fluid declined to $150 / \mathrm{mm}^{3}\left(0.15 \times 10^{9} / \mathrm{L}\right)$. Culture of the peritoneal fluid yielded Brucella spp. sensitive to ceftriaxone, rifampicin, and gentamicin.

When we further explored the patient's history, he acknowledged contact with sheep and cattle in the village in which he lived. Cultures of peripheral blood and bone marrow yielded no bacterial growth. A Brucella immunocapture-agglutination test was positive at a titer of 1/5120. An ELISA for Brucella immunoglobulin M (IgM) and $\mathrm{G}(\mathrm{IgG})$ antibodies was also positive.

Upon the final diagnosis of Brucella peritonitis, we administered treatment with oral rifampicin (300 mg twice daily) and oral doxycycline (100 mg twice daily). The patient could not tolerate the doxycycline treatment, and so the doxycycline was switched to intravenous ceftriaxone $1 \mathrm{~g}$ twice daily. The rifampicin and ceftriaxone treatment was administered for 45 days. $0 n$ the 20th day of this regimen, the WBC count in peritoneal fluid was found to be zero.

\section{DISCUSSION}

Brucellosis is a worldwide zoonotic infectious disease caused by gram-negative bacteria from the genus Brucella. The clinical presentations of brucellosis are myriad; in humans, they include fever and septicemia, and even multiple organ involvement. Because brucellosis is one of the great imitators in the world of infectious diseases, it can mimic various multisystem diseases, showing wide clinical polymorphism, which frequently leads to misdiagnosis and treatment delays, further increasing the complication rate (11).

The prevalence of brucellosis is more than 10 per 100000 population in some endemic countries. Although the disease is seen widely throughout the world, it is hyperendemic in the Mediterranean Basin, the Arabian Peninsula, India, Mexico, and Central and South America (12). Brucellosis is also an endemic disease in Turkey, where the annual incidence is 23 per 100000 population
(13). It is especially frequent in the rural areas of the middle and southeastern regions if the country, and Brucella melitensis is the most prevalent strain (14). In the presence of uremia complicated by brucellosis, neutrophils show reduced killing capabilities and modulated spontaneous apoptosis, and macrophages show inhibited NO synthesis (15). Those factors set the stage for the development of peritoneal infections in CAPD patients.

Peritonitis is a rare complication of brucellosis. Most cases of Brucella peritonitis reported in the literature (Table 1) are spontaneous bacterial peritonitis in the setting of cirrhosis (2-6). Of 5 patients with CAPD-related Brucella peritonitis reported in the literature, 4 were from Turkey (8). In 4 of the 5 patients, there was history of contact with animals and animal products, and of use of unpasteurized milk. Interestingly, fever at presentation was present in only 1 case. The most common presenting symptom was abdominal pain.

Brucellosis requires laboratory testing for diagnosis. Isolation of the organism from blood samples or other clinical specimens is the confirmatory test for the disease; however, the sensitivity of this technique depends on the stage of the illness and on other factors. Furthermore, culture does not provide a rapid result (16). Irmak et al. (16) showed that Brucella IgM and IgG flow assays had high sensitivity and specificity. That rapid and simple diagnostic test may be used to confirm brucellosis in patients living in an area endemic for the disease and clinically suspected of having it. Tests for Brucella IgM and IgG have been reported only by us and by 0zisik et al., and although results were positive in our case, results in the case reported by Ozisik et al. were negative (8). The local nature of the infection in the 0zisik et al. case may be the reason for the negative test results.

In the isolated peritoneal Brucella infection reported by Ozisik et al. (8), blood and serologic markers of systemic disease were absent, although the peritoneal fluid was shown to be infected with Brucella species. In all other reported cases (including the present case), evidence of systemic involvement was present. Our isolated peritonitis case may be a result of contamination through direct contact. Interestingly, the case reported by Alothman et al. (9) showed persistent positive serology despite long-term treatment and was considered to be chronic Brucella peritonitis.

In 3 of 5 cases, the Tenckhoff catheter was removed, but in the other 2 cases, the infection was treated with the catheter in situ. With our case included, the catheter removal rate is $50 \%$. In the case of chronic Brucella peritonitis reported by Alothman et al. (9), recurrence 


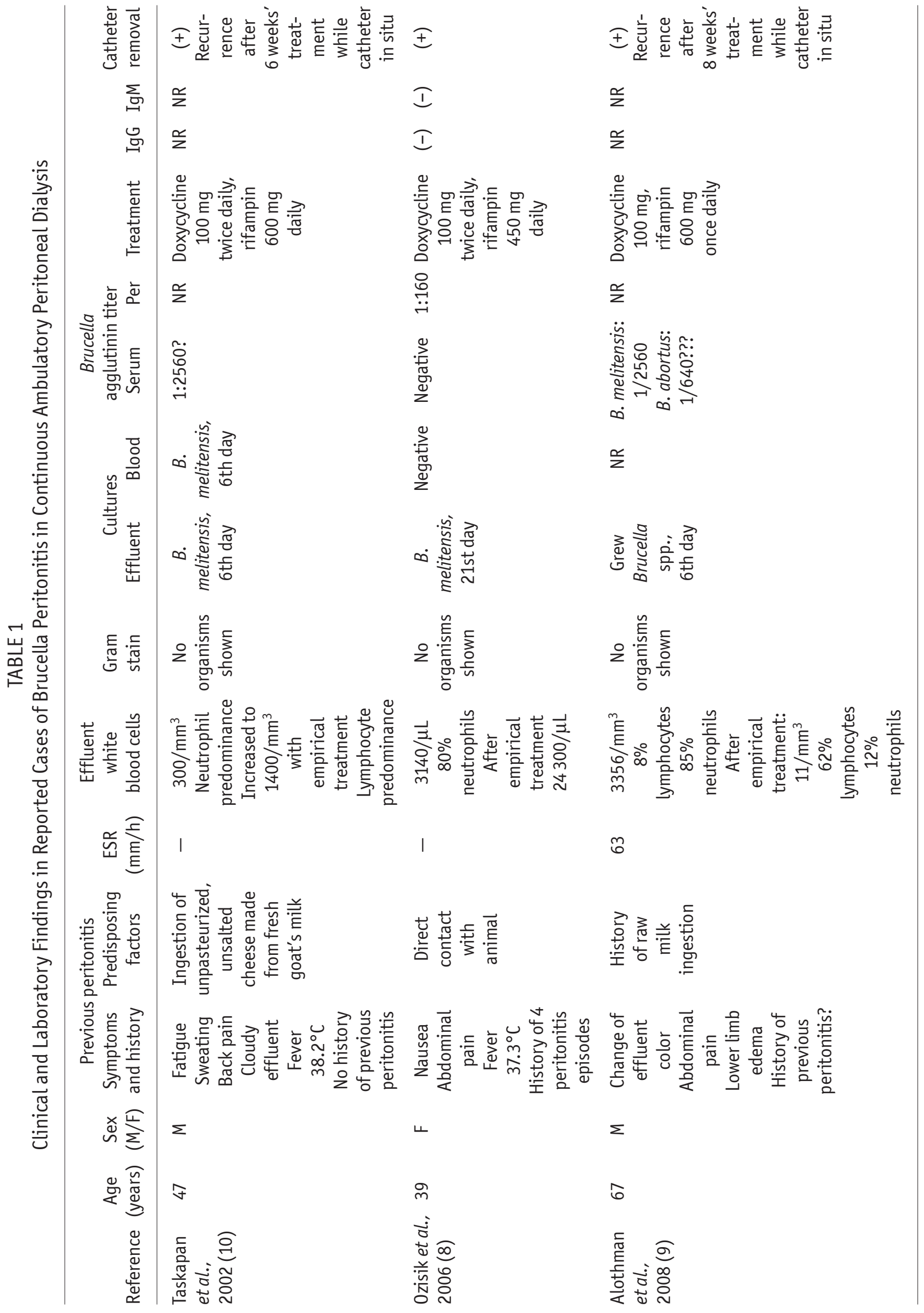

This single copy is for your personal, non-commercial use only. 


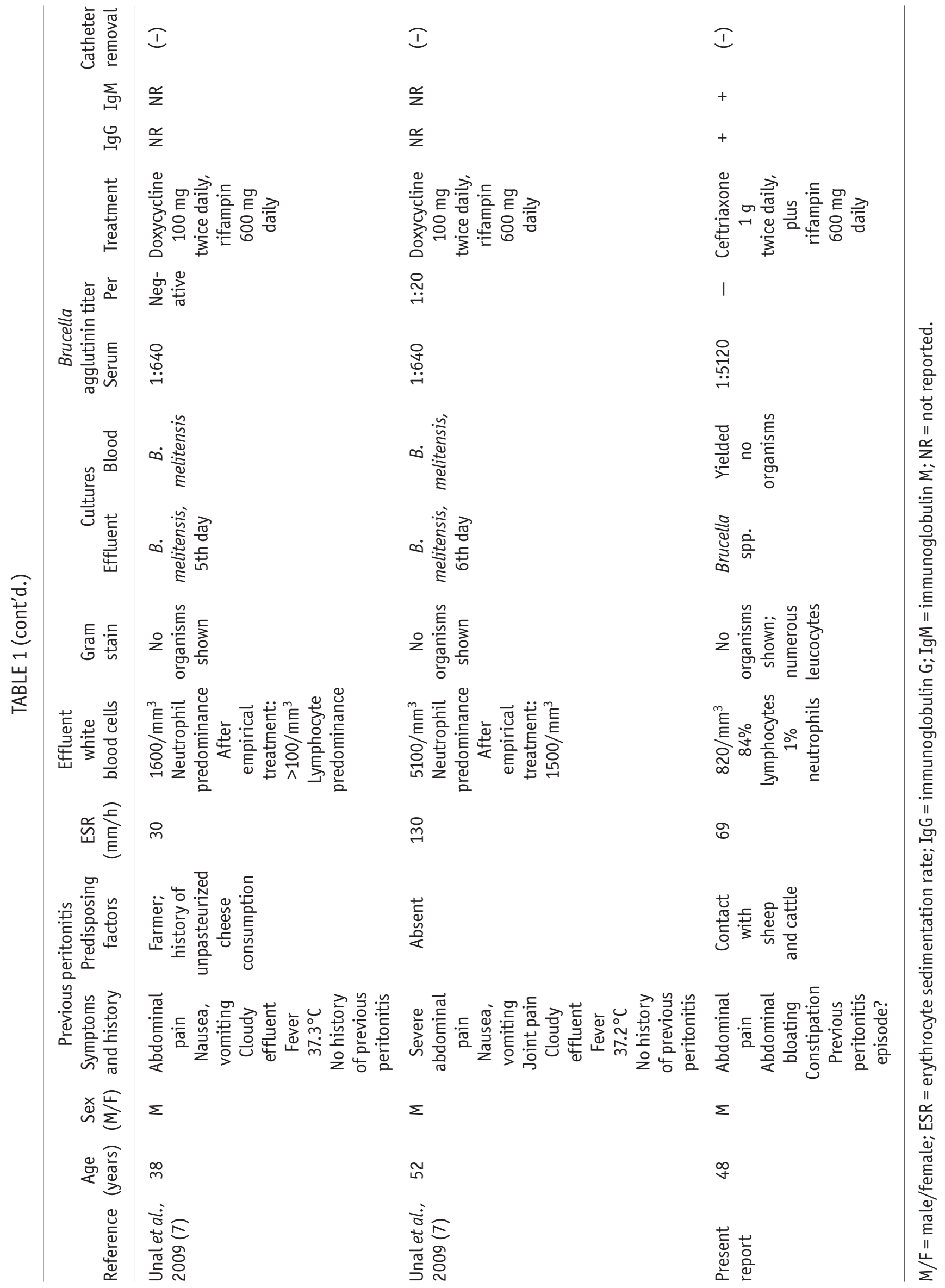

This single copy is for your personal, non-commercial use only. 
after 2 months of antibiotic treatment necessitated removal of the peritoneal catheter. Consequently, those authors suggested that removal of the peritoneal catheter should be strongly considered once CAPD Brucella peritonitis is diagnosed. However, we were able to treat our patient with the catheter in situ. In our opinion, the factors to rely on when deciding on catheter removal can include the presence of local peritonitis [as in the case reported by 0zisik et al. (8)] or the presence of severe systemic disease [as in the case reported by Taskapan et al. (10)]. In the latter case, the Brucella bacilli most probably entered through the catheter by direct contact, and thus colonization of the catheter may have occurred. Recurrence of the peritonitis after clinical and biochemical improvement lend further support to that mode of spread. If a culture of the peritoneal fluid yields Brucella bacilli, and if systemic involvement is lacking (blood cultures and Brucella IgM and IgG antibodies in blood are all negative), then it may be prudent to remove the catheter early in the infective course to prevent recurrence and treatment failure, because it seems difficult to eradicate Brucella bacilli from a contaminated catheter. Nevertheless, given that only a few cases have been reported to date, the choice to remove the catheter or to leave it in place should be judged according to the features of the individual case.

Although not reported to date in developed countries, Brucella peritonitis should be kept in mind in endemic countries. Patients living in rural areas who are involved in the care of domestic animals or who consume unpasteurized milk products are especially at risk for CAPD Brucella peritonitis. In Turkey, nephrologists prefer peritoneal dialysis for patients residing rural areas distant from hemodialysis facilities. Most of these patients are at risk for brucellosis, a factor that may hold true for other endemic countries.

One point that should be noted is the susceptibility of most strains of Brucella to ceftriaxone treatment. Because ceftriaxone is one of the empiric antibiotic options in the treatment of CAPD-related bacterial peritonitis, an initial partial response to empiric treatment may delay the diagnosis of Brucella peritonitis. If lymphocyte predominance in a WBC differential of peritoneal effluent coupled with incomplete clinical remission is encountered, then Brucella should be included with tuberculosis in the differential diagnosis.

\section{DISCLOSURES}

No author involved in the preparation of the present manuscript has a conflict of interest in any form.

\section{REFERENCES}

1. Young EJ. An overview of human brucellosis. Clin Infect Dis 1995; 21:283-9.

2. Kantarçeken B, Harputluoğlu MM, Bayindir Y, Bayraktar MR, Aladağ M, Hilmioğlu F. Spontaneous bacterial peritonitis due to Brucella melitensis in a cirrhotic patient. Turk J Gastroenterol 2005; 16:38-40.

3. Gürsoy S, Baskol M, Ozbakir 0, Güven K, Patiroğlu T, Yücesoy M. Spontaneous bacterial peritonitis due to Brucella infection. Turk J Gastroenterol 2003; 14:145-7.

4. Erbay A, Bodur H, Akinci E, Colpan A, Cevik MA. Spontaneous bacterial peritonitis due to Brucella melitensis. Scand $J$ Infect Dis 2003; 35:196-7.

5. Ozakyol AH, Sariçam T, Zubaroğlu I. Spontaneous bacterial peritonitis due to Brucella melitensis in a cirrhotic patient. Am J Gastroenterol 1999; 94:2572-3.

6. Refik Mas M, Isik AT, Doruk H, Cömert B. Brucella: a rare causative agent of spontaneous bacterial peritonitis. Indian J Gastroenterol 2003; 22:190.

7. Unal A, Sipahioglu SM, Kavuncuoglu F, Tokgoz B, Oymak 0 , Sumerkan B, et al. Peritoneal dialysis-related peritonitis caused by Brucella melitensis. Dial Transplant 2009; 38:515-16.

8. Ozisik L, Akman B, Huddam B, Azap OK, Bilgic A, Sezer S, et al. Isolated Brucella peritonitis in a CAPD patient. Am J Kidney Dis 2006; 47:e65-6.

9. Alothman A, Al Khurmi A, Al Sadoon S, AlHejaili F. Brucella peritonitis in a patient on peritoneal dialysis. Saudi J Kidney Dis Transpl 2008; 19:428-30.

10. Taskapan H, Oymak0, Sümerkan B, TokgozB, Utas C. Brucella peritonitis in a patient on continuous ambulatory peritoneal dialysis with acute brucellosis. Nephron 2002; 91:156-8.

11. Buzgan $T$, Karahocagil MK, Irmak H, Baran AI, Karsen H, Evirgen 0 , et al. Clinical manifestations and complications in 1028 cases of brucellosis: a retrospective evaluation and review of the literature. Int J Infect Dis 2010; 14:e469-78.

12. Pappas G, Papadimitriou P, Akritidis N, Christou L, Tsianos $\mathrm{EV}$. The new global map of human brucellosis. Lancet Infect Dis 2006; 6:91-9.

13. Krishnan AV, Kiernan MC. Altered nerve excitability properties in established diabetic neuropathy. Brain 2005; 128:1178-87.

14. Gür A, Geyik MF, Dikici B, Nas K, Cevik R, Sarac J, et al. Complications of brucellosis in different age groups: a study of 283 cases in southeastern Anatolia of Turkey. Yonsei Med J 2003; 44:33-44.

15. Hauser AB, Stinghen AE, Kato S, Bucharles S, Aita C, Yuzawa $Y$, et al. Characteristics and causes of immune dysfunction related to uremia and dialysis. Perit Dial Int 2008; 28(Suppl 3):S183-7.

16. Irmak $H$, Buzgan T, Evirgen 0 , Akdeniz $H$, Demiroz AP, Abdoel TH, et al. Use of the Brucella IgM and IgG flow assays in the serodiagnosis of human brucellosis in an area endemic for brucellosis. Am J Trop Med Hyg 2004; 70:688-94. 